\title{
Ball Screw Pair Design of Elevating Mechanism for Hybrid Forklift
}

\author{
Wang Yao ${ }^{1,2, a}$, Zhao Dingxuan ${ }^{1, b, *}$, Wang Lei ${ }^{1, c}, Z_{\text {Zhang Zhuxin }}^{3, d}$, Wang Lili1 ${ }^{1, e}$, \\ Hu Yanjuan ${ }^{4, f}$
}

1.College of Mechanical Science and Engineering,JilinUniversity,Changchun,China

2.College of Mechanical Engineering, BeihuaUniversity,Jilin,China

3. Engineering Training Center,Changchun Institute of Technology,Changchun,China

4.School of Mechatronic Engineering, Changchun University of Technology,Changchun,China

a1724939466@qq.com, b,* zdx@jlu.edu.cn, ${ }^{\text {a } 526794044 @ q q . c o m, ~}{ }^{\text {d } 604458252 @ q q . c o m, ~}$

e1483084809@qq.com, f37894293@qq.com

Key words: hybrid; forklift; elevating mechanism; solid modeling.

Abstract: In view of the current shortage of electric forklift hydraulic elevating mechanism, a new type of hybrid forklift elevating mechanism was proposed. The design calculation was executed according to the maximum load, elevating height, elevating speed and other related design parameters. At the same time, the solid model of elevating mechanism was modeled by CATIA software, which can provide theoretical basis for complete machine design of hybrid forklift.

\section{Introduction}

In recent years, the great development of the logistics industry provides a broad development stage for the loading and unloading forklift of short-distance transportation, and the demand of forklift is increasing at a rate of twenty percent per year. However, along with strengthening of people's environmental protection awareness, emission from combustion engine is strictly controlled [1, 2]. Because mature technologies and reliable quality of hybrid cars, it will have broad future to develop hybrid forklift. Some hybrid forklifts have been entered people's horizons.

According to power plant, fork lift can be ranged into two principal types which are battery electric forklift and engine forklift. Internationally, the former's work focused on AC drive technology, hydraulic pump motor control technology and electronic steering technology; whereas, the latter's work focused on reducing the fuel consumption of engine [3, 4]. In the hydraulic system, with the flow of fluid, there is a considerable amount of fluid energy loss. The energy loss can be seen not only the internal friction loss in the process of the fluid flow, but also the volumetric loss of system. It sent the system energy utilization down and could not raise the transmission efficiency [5]. High consumption and low efficiency increased temperature of the fluid. It influences the reliability of the system work and prolongs the work time of hydraulic elements. But it's not battery electric forklift but engine forklift, Load (including goods and working device) lifting is the most typical work conditions, so study on potential energy recovery will bring obvious results of energy saving. If not energy recovery, in the most potential energy of decline changed to heat energy, caused fever of hydraulic system, and some damage of the hydraulic component in the system. Thus, research on the potential energy recovery has great significance on improving the 
service life of the forklift.

\section{The principle of elevating mechanism of battery electric forklift}

Elevating Mechanism of battery electric fork lift truck is composed of the upright mounting , the fork arms , the hydraulic cylinder 、 the roller bearing and chains and chain wheels. The upright mounting is hinged on the bracket of the front axle body, consists of a set of parallel steel frame (the inner upright mounting and the outer upright mounting) and sliding bracket fixed fork (fork arms frame). The fork arms are bent $90^{\circ}$, they are tools of carrying load and installed on slide out hangers with the inner upright mounting lifting. Chain wheel setcan lift the slide out hangers. Forklift trucks generally use two chains, were hung in two sprockets. The end of chain fixed outer upright mounting, and the other end is fixed on slide out hangers. The lifting hydraulic cylinder generally has two sets of telescopic sleeve hydraulic cylinder, which is installed on the outer upright mounting. When the distribution valve lifting handle is allocated to the lifting position, the high-pressure oil flows into the lifting oil cylinder, by pressure of the high-pressure oil, and the plunger hydraulic cylinder drives inner upright mounting lifting. At the same time, the chain drives the slide out hangers lifting in relation to the inner upright mounting. When the inner upright is mounting up to the limit, the slide out hangers also reaches the maximum lift height of fork truck. When the distribution valve lifting handle back to the middle position, cut off the oil pressure supplies, lifting oil cylinder stay in their current position. At this moment, the fork arms keep the current constant height. When the distribution valve lifting handle is shifting to the fall position, the hydraulic oil of lifting oil cylinder flows back to the oil tank by gravity of the slide out hangers. Lift cylinder piston drops, inner upright mounting were dropping in relation to the outer upright mounting. At the same time, the slide out hangers dropping in relation to inner upright mounting, make the fork arms drops to the ground.

\section{Design mechanism of the elevating mechanism of hybrid forklift}

In view of the present status about insufficient high oil temperature, high energy consumption, low efficiency, presents a new hybrid forklift elevating mechanism. A new type elevating mechanism for hybrid forklift is composed of the ball screw pair, AC motor, brake and chains and chain wheels.

1) The ball screw pair. The ball screw nut is fixed on the inner upright mounting abdominal plate. By reversing of the ball screw, screw nut moves vertically, realizes forklift arms rising and falling.

2) Brake. Due to the high efficiency of ball screw driving, not self-locking. Using vertical bearing transmission, it need to prevent reverse rotation by the weight of the components produced when the drive is stopped or motor power failure without balance weight components. To prevent reverse rotation can be driven by a motor or cannot reverse overrunning clutch transmission, transmission device can also be used to reverse (worm drive as capable of self-locking) and electromagnetic or hydraulic brake. Here, we can use the electromagnetic brake.

3) AC motor. To make the forklift can lift goods, and provide the impetus needed portal frame. AC motor is the power source of the upright mounting motion.

4) Synchronous belt transmission mechanism. Synchronous belt transmission mechanism is to provide energy device from the AC motor drive device to inner upright mounting. AC motor through the synchronous belt transmission drives the ball screw to rotate, realized lifting of fork arms. The maximum load is 3 tons, it may cause synchronous belt loose after a short period of time. Therefore, synchronous belt transmission needs tightening mechanism. 


\section{Calculation of the elevating mechanism of hybrid forklift}

1) Calculation of the ball screw pair Equivalent load $\mathrm{F}_{m}$ :

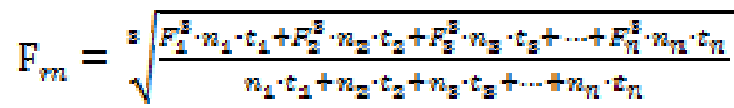

$F_{1}, F_{2}, F_{3}, \cdots, F_{n}---$ axial load

$n_{1}, n_{2}, n_{3}, \cdots, n_{n}--$ speed correspond to $F_{1}, F_{2}, F_{3}, \cdots, F_{n}$

$t_{1}, t_{2}, t_{3}, \cdots, t_{n}---$ time correspond to $F_{1}, F_{2}, F_{3}, \cdots, F_{n}$

Equivalent speed $\mathrm{n}_{m}$ :

$\mathrm{n}_{m}=\frac{n_{1} \cdot t_{1}+n_{2} \cdot t_{2}+n_{z} \cdot t_{z}+\cdots+n_{n} \cdot t_{n}}{t_{1}+t_{2}+t_{z}+\cdots+t_{n}}$

Rated dynamic loads $\mathrm{C}_{a m}^{\prime}$ :

$C_{a m}^{\prime}=\frac{f_{w} \cdot F_{m}\left(60 \times m_{m} \cdot L_{h}\right)^{\frac{2}{3}}}{100 \times f_{a} \cdot f_{0}}$

$f_{a}$ - coefficient of accuracy

$f_{o}$ - coefficient of reliability

$f_{w}-$ coefficient of load property

$L_{n}$-expected operational life

static loads $\mathrm{C}_{o a}$ :

$f_{o} F_{m \max } \leq C_{o a}$

$f_{o}$ - coefficient of safety

$F_{\text {nmax }}$ - maximum axial load of ball screw pair

Through calculations, the outer circulation intubation type double nut gasket preloaded ball screw is selected, nominal diameter is $63 \mathrm{~mm}$, lead is $12 \mathrm{~mm}$, ball diameter is $7.144 \mathrm{~mm}$.

2)Brake type selection

$T_{a}=\frac{\left(F_{a} l\right)}{2 \times 3.14 \times \eta_{1}}$

$T_{a}$-torque

$F_{a}$ - axlal load 
I- lead of ball screw pair

$\eta_{1}$ - forward efficiency of ball screw pair

Rated torque is 265.4 N.M, rated voltage is $80 \mathrm{~V}$, allow maximum rotating speed is $3000 \mathrm{r} / \mathrm{m}$, the electromagnetic brake is selected.

3) Synchronous belt transmission mechanism type selection

Design Power $\mathrm{P}_{d}$ :

$P_{\mathrm{d}}=K_{A}=P$

$K_{A}-$ coefficient ofconditions

$F_{a}$-transfer power

Pitch diameter of bigger belt wheel $d_{2}$ :

$d_{2}=\frac{P_{d} \cdot z_{2}}{\pi}=i \cdot d_{1}$

Belt length $\mathrm{L}_{o p}$ :

$L_{o p} \approx 2 \alpha_{0}+\frac{\pi}{2}\left(d_{2}+d_{1}\right)+\frac{\left(d_{2}-d_{1}\right)^{2}}{4 a_{0}}$

centre-to-centre separation $a$ :

$a \propto a_{0}+\frac{L_{p}-L_{u p}}{2}$

Belt width $b_{a}$ :

$b_{a} \geq b_{a q} \sqrt[1144]{\frac{P_{d i}}{R_{a} \cdot P_{q}}}$

$b_{a 0}-$ standard belt width

$K_{a}$ - coefficient of smaller belt meshing tooth number

According to calculated, three-dimensional hybrid forklift elevating mechanism plotted by CATIA software. After drawing, a test of interference detection was conducted. Assembly sequence planning are the key technologies in virtual assembly.

\section{Conclusions}

The problems of general electric forklift hydraulic lifting mechanism are high energy consumption, low efficiency. A novel hybrid forklift lifting mechanism adopts a motor to drive screw rotation, and then lifting fork, can realize the lifting 0-3 tons of cargo through the calculation, enhance the speed of $0.3 \mathrm{~m} / \mathrm{s}$, fully meet the forklift job requirements. At the same time, using the electric drive, the efficiency can reach above 90 percent, which overcomes the shortcomings of the hydraulic lifting mechanism.

High reliability, superior performance of the new hybrid forklift is bound by the user's welcome. 


\section{Acknowledgment}

The research is funded by National High Technology Research and Development Program 863(2009AA044403) and 985 Program of Jilin University.

\section{References}

[1] A. Widyotriatmo, K.S. Hong and L. H. Prayudhi. Robust stabilization of a wheeled vehicle: Hybrid feedback control design and experimental validation. Journal of Mechanical Science and Technology, 24(2010) 513 520.

[2] V. Girbés, L. Armesto, J. Tornero. Path following hybrid control for vehicle stability applied to industrial forklifts. Robotics and Autonomous Systems, 62(2014) 910-922.

[3] L.T. Lam, R. Louey. Development of ultra-battery for hybrid-electric vehicle applications. Journal of Power Sources, 158 (2006) 1140-1148.

[4] T.M. Keränena, H. Karimäki, J. Viitakangas, et al. Development of integrated fuel cell hybrid power source for electric forklift. Journal of Power Sources, 196 (2011) 9058-9068.

[5] E. Hosseinzadeh, M. Rokni, S. G. Advani, A. K. Prasad. Performance simulation and analysis of a fuel cell/battery hybrid forklift truck. International Journal of Hydrogen energy, 38(2013) 4241-4249. 